\title{
A ESCOLA DE VETERINARIA NA UNIVERSIDADE DE SANTIAGO*
}

\author{
Por \\ MARGARITA BARRAL MARTÍNEZ**
}

\section{RESUMO}

Aínda que Eugenio Montero Ríos foi un dos grandes primates do caciquismo desenvolvido durante a etapa da Restauración, o seu papel de padroado na cidade de Santiago e de mecenado na Universidade compostelá tiveron unha importancia considerable, un tema descoñecido ou mesmo esquecido por tódalas connotacións negativas coas que comunmente e de xeito simplista se asocian ó termo cacique. A Universidade de Santiago medrou ó carón da protección que lle prestou Montero dende que saíra representante deste distrito en 1886 e a súa forte influencia no Goberno central de Madrid permitiulle acadar concesións trascendentais para dita institución, como foi o caso da Escola de Veterinaria.

\section{PALABRAS CLAVE}

Montero Ríos, Restauración, Cacique, Mecenado, Escola de Veterinaria.

* O presente artigo foi presentado no Nadal de 2000.

** Bolseira predoutoral da Secretaría Xeral de I+D (Xunta de Galicia).

«CUADERNOS DE ESTUDIOS GALLEGOS», Tomo XLIX, Fascículo 115, Santiago 2002. 


\begin{abstract}
Although Eugenio Montero Ríos was one of the big ones primates of the system of dominance by the local boss developed during the stage of the Restoration, his patronage paper in Santiago's city and of patronage in the University of Santiago had a considerable importance, an unknown topic, or even forgotten by all the negative connotations with those that commonly and in a simplistic way they associate to the term cacique. The University of Santiago grew beside the protection that Montero lent him since representative of this district had left in 1886 and his strong influence in the central Government from Madrid it allowed him to reach momentous concessions for this institution, like it has been the case of the School of Veterinary Science.
\end{abstract}

\title{
KEYWORDS
}

Montero Ríos, Restoration, Cacique, Patronage, School of Veterinary.

\section{INTRODUCCIÓN}

As Facultades de Filosofía e Letras, a de Ciencias e a sección de Dereito Administrativo ata a licenciatura permaneceran na Universidade de Santiago dende 1845 e ata 1869 , ano no que foron suprimidas. Algún tempo despois, concretamente en 1881, a Deputación de A Coruña acordou solicitar ó Goberno central o restablecemento destes estudios e unha vez informado o Concello de Santiago do proxecto a Municipalidade secundou a demanda de seguido ó tempo que se puxo en contacto co Deputado a Cortes por Acumulación E. Montero Ríos remitíndolle unha carta, acompañada da exposición enviada ó Goberno, onde lle solicitaban que apoiase a demanda no Congreso dos Deputados. Ante esta petición o Deputado non se demora en respostar e o 23 de novembro con outra carta ó Alcalde de Santiago, Felipe Gutiérrez de la Peña, dicía:

«CUADERNOS DE ESTUDIOS GALLEGOS», Tomo XLIX, Fascículo 115, Santiago 2002. 
Muy Sr. mío: Tengo el gusto de manifestarle a V.S. que al recibir la exposición que para las Cortes la Excma. Corporación de su digna presidencia, remitió pidiendo el restablecimiento de varias enseñanzas en esa Universidad y a la Comisión de presupuestos, con el beneplácito de los Sres. Ministro de Fomento y de Hacienda habian incluido en el de Fomento la partida necesaria para completar la enseñanza en la sección de Ciencias Físico-Químicas de la Facultad de Ciencias hasta la Licenciatura y para establecer una ESCUELA DE VETERINARIA. En este presupuesto no ha sido posible obtener mayor desarrollo de la enseñanza en ese puesto, pero confiamos que ya en el próximo habrá de conseguirse algo más.

A tan satisfactorio resultado han contribuido todos los señores diputados y senadores de las cuatro provincias de Galicia, gestionando con el senador por esa Universidad y conmigo los autos, en representación de todos ellos una Comisión compuesta de los Sres. Romero-Ortiz, Álvarez Bugallal, Linares Rivas, Martínez, Orense, Pardo Montenegro, Quiroga, Urzáiz y Medina Vitores, los cuales con el más vivo celo han contribuido muy eficazmente al éxito obtenido.

(...) Ruego a V.S. que al poner en conocimiento de la Excma. Corporación las noticias que le comunico, se sirva ofrecerle también el testimonio de mi profundo respecto y de mi deseo de emplearme siempre en su servicio y de su Ilustre ciudad. (...) $)^{1}$.

\section{E. MONTERO RÍOS (Santiago, 1832-Madrid, 1914)}

Eugenio MONTERO RÍOS naceu en Santiago o 13 de novembro de 1832 sendo o cuarto irmán no seo dunha familia que dispuña duns ingresos non moi suficientes para sacar adiante unha prole de cinco fillos ${ }^{2}$, sen embargo, chegou a ser un personaxe da historia de Galicia que poderiamos

\footnotetext{
${ }^{1}$ ARQUIVO HISTÓRICO UNIVERSITARIO. Serie Universidad. Antecedentes varios. 1834-1899.

${ }^{2}$ O seu pai, Ángel Montero, era «escribano de Audiencia» e a sua nai, Francisca del Río, foi unha dona con fortes crenzas relixiosas e que tentou inculcarllas ós seus fillos.
}

«CUADERNOS DE ESTUdIOS GALLEGOS», Tomo XLIX, Fascículo 115, Santiago 2002. 
definir como intelixente, contradictorio e mesmo complexo de entender aínda que en realidade saibamos moi pouco del e do tempo que lle tocou vivir para o caso de Galicia, agravado isto ca existencia dunha memoria popular enchida de tópicos e anécdotas que difícilmente poderiamos saber se foron realmente certas ou producto desa mesma memoria máis ou menos real.

Montero Ríos non escribiu libros pero sí pronunciou abundantes discursos e conferencias e foi o autor de leis trascendentais para a historia do Estado español, chegando a ser o político do dereito durante o SEXENIO REVOLUCIONARIO (1868-1873), momento no que o xurisconsulto galego naceu á vida política ó formar parte da Comisión encargada da redacción da Constitución de 1869, onde a liberdade de culto que se establecía nos artigos 20 e 21 foi sobre todo unha tarefa desenvolvida polo mesmo Montero Ríos. Como Ministro de Gracia e Xustiza neste período democrático ${ }^{3}$ loitou pola aprobación de leis como a Lei de Rexistro Civil (1870), Lei Hipotecaria (1870), Lei orgánica do Poder Xudicial (1870) que estivo vixente máis dun século, Lei de Matrimonio Civil (1871), Reforma do Código Penal (1871), Lei de Procesamento Criminal (1872) e un longo etc., o que veu a determinar que Montero contribuira na realización práctica de aspectos fundamentais do liberalismo no relativo ós eidos da relixión e da xustiza; a ideoloxía política de Montero foi a do liberalismo progresista pero o que nos pode resultar paradóxico no seu caso é o feito de que ó mesmo tempo que defendía e promulgaba unha lexislación que se atopaba ca resistencia máis recia por parte da Igrexa, se declarase profundamente relixioso, como de certo o foi. Montero tivera unha formación fortemente católica durante os primeiros anos da sua vida e mesmo chegara a cursar ata cuarto de Teoloxía no Seminario de Santiago pero foi aquí cando decidiu abandonar a sua carreira clerical recoñecendo quizais que era máis unha imposición externa, pola influencia familiar, que unha vocación de seu; sen embargo, sempre se declarou católico practicante e desexaba que os seus fillos seguiran o mesmo camiño. Defendía unha

\footnotetext{
${ }^{3}$ Montero Ríos detentou un total de cinco veces a Carteira de Gracia e Xustiza durante o Sexenio, tres veces ó longo do ano 1870 en Gobernos presididos por Juan Prim y Prats e nas outras dúas ocasións en 1871 e 1872 respectivamente, con Ruiz Zorrilla como Presidente e dentro xa do reinado de Amadeo I, Duque de Aosta.
}

«CUADERNOS DE ESTUDIOS GALLEGOS», Tomo XLIX, 'Fascículo 115, Santiago 2002. 
concepción de Igrexa compatible ca liberdade política polo que poderiamos dicir que a súa figura foi representativa da corrente do liberalismo católico que tamén existiu en España por este tempo (Dardé, C., 1993).

Trala caída do Sexenio democrático, Montero Ríos protagonizou un voluntario afastamento da política activa e mantívose illado da vida pública durante a I REPÚBLICA (1873-74) e os primeiros anos da RESTAURACIÓN BORBÓNICA (1874-1923), por rexeitamento tanto dos postulados federais coma dos conservadores que simbolizaba a figura de Cánovas del Castillo e a Constitución de 1876. Montero, coma outros progresistas do momento, abandonou a Cátedra ${ }^{4}$ ca chegada de Cánovas ó poder e en solidaridade cos Catedráticos da Universidade compostelá González de Linares e Laureano Calderón que foran expulsados en 1875 pola denominada segunda cuestión universitaria. Neste ambiente de protesta foi onde naceu a Institución Libre de Enseñanza, no ano 1876 e da que Montero chegou a ser Rector en 1877-78.

Pero este retraemento político de Montero Ríos durou pouco tempo en realidae e como el mesmo dixo, (...) restaurados los Borbones, requerimientos determinados y mi amor a la democracia, me tornaron a la lucha, aceptando lealmente y con la misma decisión con que había servido a la de Saboya, a la dinastía restaurada. (La Voz de Galicia, 13.05.1914). Entre os anos 1881 e 1885 volveuse a introducir na vida política do Goberno central e neste derradeiro ano asinou con Alonso Martínez a «Lei de Garantías» onde se vencellaron tódalas fraccións liberais e que logo levou ó nacemento do Partido Fusionista en 1886 baixo o liderazgo de Práxedes Mateo Sagasta; poderiamos dicir que dende entón comezou o sistema turnista ideado por Cánovas e que veu a supor a alternancia pacífica no poder entre liberais e conservadores, un sistema que dominou a vida social e política do país a través da figura dos caciques e do control absoluto do sistema electoral, fraudulento e amañado a través do sistema do encasillado. No ano 1889 Montero e Senador vitalicio e dende entón volveu a destacar na política do país e foi quen de artellar unha ampla

\footnotetext{
${ }^{4}$ En 1860 gañara por oposición a Cátedra de Disciplina Eclesiástica para a Universidade de Oviedo pero a través dunha permuta con Guilleermo Estrada acadou o traslado como profesor da mesma disciplina para a Facultade de Dereito da Universideade de Santiago.
} 
rede de influencias políticas e de familia que permitiron catalogalo como un dos primates do caciquismo da Restauración, sobre todo dende a derradeira década do século XIX.

A influencia política de Montero exerceuse na sua rexión natal a través do control dalgúns distritos electorais e sobre todo dende que en 1886 queda xa definitivamente nomeado Deputado polo distrito de Compostela, de xeito directo ata 1891 e indirecto dende ese ano de 1891 e ata 1917 , cando son os seus xenros primeiro e logo despois un dos seus fillos os que pasan a representar o distrito e a secunda-lo monterismo en Santiago de Compostela ${ }^{5}$. Dende entón desenvolveu un protectorado cara á súa cidade natal e foi quizais o eido do ensino un dos máis favorecidos pola súa influencia. Un exemplo importante deste mecenado caciquil que desenvolveu en Santiago foi a concesión dunha Escola Universitaria de Veterinaria.

\section{A ESCOLA DE VETERINARIA}

\section{Antecedentes}

Nunha Comisión de Senadores e Deputados galegos na que posiblemente tamén se atoparía Montero Ríos e que se desenvolveu en Madrid a finais de 1881, acordouse pedir a construcción dunha Escola de Veterinaria para Santiago. Incluida nos presupostos confeccionados para o ano 1882 ca cantidade de 42.000 pesetas, esta foi instada ó ano seguinte, en 1882 e no Colexio de San Clemente ${ }^{6}$. Contaba neste edificio cunhas dependencias que axiña se converteron en insuficientes polo seu reducido espacio ${ }^{7}$, compartido ademáis ca Escola de Artes e Oficios, ca

\footnotetext{
${ }^{5}$ No ano 1891 a Acta de Compostela pasou a ser representada polo seu xenro Benito Calderón Ozores pero a morte repentina deste ó ano seguinte fixo que dende 1893 fora outro dos seus xenros, Manuel García Prieto, o que representara este Distrito ata 1912, momento no que o titular agora será xa un dos fillos consanguíneos de Montero, concretamente Eugenio Montero Villegas, unha representación que levou a cabo ata 1917.

${ }^{6}$ Hoxe Instituto de Bacharelato Rosalía de Castro.

${ }^{7}$ A superficie total do antigo Seminario de San Clemente era de 7.931 metros cadrados, dos cales 4.355 metros correspondía o edificio propiamente dito e os restantes 3.576 a horta.
}

«CUADERNOS DE ESTUDIOS GALLEGOS», Tomo XLIX, Fascículo 115, Santiago 2002. 
Sociedade Económica de Amigos do País e máis tarde ca Facultade de Dereito, que foi trasladada provisionalmente ó citado Colexio entre os anos 1894-1901 polas obras de Reforma do Edificio da Universidade.

No ano 1889 os cataláns comezaron a movilizarse para que a Escola fora trasladada á sua rexión e Montero Ríos, unha vez que tivo coñecemento desta pretensión, tomou contacto directo co asunto e visitou ó Ministro de Fomento e ó Director Xeral de Instrucción Pública para tentar impedir o posible traslado e xustificaba as súas argumentación na condición gandeira e agraria por excelencia da rexión galega. Ainda que a Escola continou funcionando, a supresión no Proxecto de Lei de Presupostos para o ano 1890 da partida económica destiñada para a Escola deu lugar a unha forte campaña de petición dunhas dependencias exclusivas para este estudio por parte de tódalas Corporacións galegas, é dicir, pasouse a reivindicar a construcción dun edificio ad hoc onde os estudios de Veterinaria poidese ampliar e desenvolver o seu programa de ensino e experimentación; foi así cando en outubro de 1894 o Rector Maximino Teijeiro Fernández envia unha circular ó Alcalde Ramón Sanjurjo y Pardiñas Montenegro, Marqués de Casa Pardiñas, solicitando se xestionase a construcción do citado edificio. A proposta tivo moi boa acollida no Concello e unha mostra disto foi o feito de que se aprobou ceder gratuitamente o solar necesario para as obras e así llo comunicou por carta ó Director Xeral de Instrucción Pública, un dos xenros de Montero, Eduardo Vincenti, que de seguido dispuxo fora o Arquitecto Antonio Bermejo y Arteaga o encargado da formalización do proxecto mediante a elaboración dos planos, inspirados na Escola francesa de Alfort. Sen embargo, o pasamento de Bermejo na etapa anterior á construcción do Edificio propiciou que fora sustituido por Arturo Calvo, quen modificou un chisco o tratamento do corpo central. Durante o ano de 1894 tamén se nomeou unha Comisión especial para encargarse da construcción do proxecto e para estudiar a adquisición dos terreos ${ }^{8}$, unha vez que estiveron rematados os planos do Edificio en 1895, no ano 1898 Manuel García Prieto remíteos dende Madrid despois de que fora o mesmo Ministro de

${ }^{8}$ Esta Comisión especial estaba constituida polos seguintes señores: Casimiro Torre Sánchez, Luciano Sánchez Miramontes, Eduardo Vassallo Roselló e Francisco Piñeiro Pérez.

«CUADERNOS DE ESTUDIOS GALLEGOS», Tomo XLIX, Fascículo 115, Santiago 2002. 
Fomento quen llos entregara, ó tempo que se establece tamén que a construcción do novo edificio sería nos terreos chamados Codeseira, entre a rúa do Hórreo ou estrada Santiago-Ourense e o río Sar.

Sobre a cuestión de se houbo algún tipo de negociación á hora de escoller o solar máis idóneo para o emprazamento do Edificio non está moi claro, tal e como se reflicte na correspondencia anteriormente citada, aínda que tamén é certo que o espacio final que se escolleu cumpría con certas esixencias de hixiene, ó ser esta unha paraxe elevada e polo tanto ventilada, moi axeitada para a construcción desta Escola na que se proxectaban instalacións accesorias como unha granxa experimental e unha estación pecuaria. Aínda así, houbo posturas contrarias a este emprazamento, como foi a desenvolvida polo Concelleiro Manuel López López durante o ano 1894 e que opostaba por unha mellor localización do Edificio na Horta de San Martín'. Este emprazamento non tivo adeptos.

Nunha primeira R.O. do 2 de septembro de 1898 aprobouse o proxecto de construcción do edificio cun presuposto de $982.324,05$ pesetas e o Concello en sesión extraordinaria do día 5 de septembro acordou (...) consignarse en acta el agradecimiento de la Corporación hacia el Gobierno de S.M. y muy especialmente al Excmo. Sr. D. Eugenio Montero Ríos, autor de esta idea y de su desarrollo ${ }^{10}$.

Ainda que nesta primeira subasta da obra foi concedida a Antonio Rodríguez Aranga, de Madrid, o contratista que finalmente se encargou da construcción foi Juan Bouzón Figueroa, veciño de Santiago, unha contratación que acadaría noutra subasta que se artellou para a concesión das obras en 1902 e despois de que na segunda R.O. do 11 de xullo de 1902 fose aprobada a concesión. Poderiamos supor por esta razón que o proxecto foi suspendido entre 1899 e 1902.

As obras de construcción retrasáronse polos trámites de expropiación das terras ó atoparse nalgúns casos problemas e trabas importantes relacionados con incapacidades para vender os terreos por parte dalgúns propietarios e albaceas testamentarios, o que mesmo chegou a determinar que nalgún intre o Alcalde e a Comisión pensaran na elección dun

\footnotetext{
${ }^{9}$ Correspondería á zona onde hoxe se atopan as Facultades de CC. da Educación e Enfermería da Universidade de Santiago de Compostela.

${ }^{10}$ ARQUIVO HISTÓRICO UNIVERSITARIO. Escuela de Veterinaria. 1894-1912.
} 
emprazamento alternativo para a nova construcción, o Agro do Outeiro, situado entre o Paseo de Bóveda e o Barrio de San Lorenzo.

No derradeiro trimestre dese mesmo ano de 1899 o Goberno, a través da Lei de Presupostos que presentou á aprobación das Cortes, propuña as supresións da Facultade de Deito e da Escola de Veterinaria do conxunto docente da Universidade de Santiago; isto fixo que se desenvolvese unha forte campaña de opinón pública en contra do proxecto en particular e en contra do Goberno de Silvela en xeral ${ }^{11}$. A prensa da rexión participou tamén no movemento de protesta iniciado en Santiago e que tivo repercusión mesmo no resto do Estado. Formouse unha Comisión Popular para dirixir unha Exposición ás Cortes firmada polos veciños e remitida por mediación do seu Deputado, Manuel García Prieto. A Exposición de la Ciudad de Santiago de Galicia a las Cortes del Reino, con data do $1^{\circ}$ de novembro de 1899 e redactada por Alfredo Brañas, foi rotunda e concisa e falaba de tres tipos de razóns que imposibilitaban a supresión: científico-educativas, xurídicas (alegando que a supresión viña a ser un despoxo ó ser a Universidade de Santiago de creación pontificia) e económicas (a Universidade ingresara ó Tesouro público durante o curso 1898-99 un total aproximado de 45.058 pesetas,e a Escola de Vetarinaria só custara 93 pesetas durante o mesmo período lectivo). A Exposición remataba cas seguintes verbas:

(...) Las Cortes, en su alta previsión y en su espíritu de prudencia, juzgarán una grave, inmotivada y fuera de todo cálculo y razón es la ofensa que a la ciudad de Santiago se infiere. Sucumbiremos ante la fuerza y ante la amenaza, pero protestando ante Dios, y ante la Historia de lo que puede llegar a ser un atentado contra los derechos sagrados de un pueblo, sumiso y disciplinado, que solo enarboló sus pendones para defender la santa unidad e integridad de la gran patria española.

Terminamos diciendo a las Cortes del Reino que en vistas de las vigorosas e irrefragables razones en que nos fundamos, se opongan

\footnotetext{
${ }^{11} \mathrm{O}$ conservador Francisco Silvera accedera á Presidencia do Consello de Ministros (por primerira vez) o 4 de marzo de 1899, un cargo que desenvolveu ata o 23 de outubro de 1900, momento no que foi substituído por Marcelo de Azcárraga.
} 
resueltamente, en nombre de la justicia ofendida y del derecho ultrajado, a la supresión de la Facultad de Derecho de la Universidad de Santiago y de la Escuela especial de Veterinaria, porque llegaría a ser una peligrosa perturbación en el orden social, jurídico y económico de Galicia $^{12}$.

Ademáis disto, o Alcalde de Santiago, Casimiro Torre, e os Concelleiros Pena e Lalinde visitan a Montero, quen lles dixo estar moi sorprendido pola desagradable nova e que xa fixera as súas xestións pertinentes a favor de Santiago. No comunicado do día 3 de novembro que o mesmo Alcalde presentou ó Concello dando conta da entrevista mantida con Montero en Lourizán por él e polos Concelleiros citados, dicía:

(...) De labios del insigne Canonista hemos oido que al encontrarse sorprendido por la desagradable noticia de la supresión de la Facultad de Derecho y de la Escuela de Veterinaria de esta ciudad, habia dado los primeros pasos en el camino de sus gestiones a favor de Santiago. Manifestó además que está y estará siempre dispuesto a hacer todo género de sacrificios en obsequio de esta población y de sus centros de enseñanza, y que al regresar dentro de muy breves días a Madrid, dedicará toda su atención a este asunto. (.... $)^{13}$.

O texto da Exposición remitida ás Cortes axiña foi publicado e difundido por toda Galicia e supuxo unha reivindicación que superou os límites da defensa da Facultade de Dereito e da Escola de Veterinaria. Pero a realidade da cuestión mesma radicaba nun asunto político, algo moi característico na etapa da Resturación: baixo esta aparente unión do Claustro e do pobo compostelán o certo foi que este enfrentamente nacera na elección para a Senaduría da Universidade que se desenvolvera facía pouco tempo e onde existiran dúas candidaturas: a dos monteristas que apoiaba a Salvador Parga e a outra, defendida polos rexionalistas e encabezados nesta cuestión por Alfredo Brañas, que defendía

\footnotetext{
${ }^{12}$ ARQUIVO HISTÓRICO UNIVERSITARIO. Op. cit.

${ }^{13}$ Ibidem.
} 
a Eduardo Hinojosa ${ }^{14}$, o que saíra finalmente elixido, un andaluz de dereitas fortemente católico e totalmente descoñecido polo Claustro, moi alleo polo tanto ós intereses da Universidade de Santiago e da sua comarca, coma tódolos cuneros. Ademáis, era de condición pidaliana, é dicir, adepto do Marqués de Pidal, Ministro neste momento e cuio feudo era Oviedo, o que xustificaría que a supresión dentro das Universidades do noroeste fose en Santiago e non en Oviedo. Evidentemente, o proxecto de supresión deixou muy mal parados ós rexionalistas, que foran os que apoiaran a candidatura de Hinojosa, polo que tentaron soluciar a cuestión liderando o movemento de protesta popular, de ahí que fose Alfredo Brañas o encargado de redactar a exposición que se remitiu ás Cortes.

O día 22 dese mesmo mes de novembro chega a Santiago un telegrama procedente de Madrid e remitido por García Prieto no que se comunica:

Ministro de Fomento participó esta mañana al Sr. Don Eugenio propondrá a la Comisión de Presupuestos el restablecimiento de los créditos para la continuación de la Facultad de Derecho y Escuela de Veterinaria. La Comisión acaba de aprobarlos. Una vez más ha demostrado su inmenso cariño por Santiago Don Eugenio a quien débese feliz resultado que me apresuro a participarle ${ }^{15}$.

Volvendo ó tema da expropiación do solar escollido para a construcción do novo edificio, temos que ó remate levouse a cabo a expropiación forzosa obtida do Estado. O día 7 de febreiro de 1899 publícase a R.O. da entrega do solar e dez días despois aparece a acta de entrega ó Estado da terra coñecida polo nome de Tenencia do Hórreo e que viña a ocupar as Agras de Tenencia, Cornide de Arriba e de Abaixo, Codeseiro de Arriba e Prados das Brañas do Sar, un total de 32 parcelas que supuñan unha extensión de 59.856 metros cadrados. A R.O. do 11 de xuño de 1902 autori-

\footnotetext{
${ }^{14}$ No momento desta elección, Eduardo Hinojosa era Director Xeral de Instrucción Pública. Para esta cuestión ver: CORES TRASMONTE, B., Os Senadores da Universidade de Santiago, Cuadernos de Estudios Gallegos. Anexo XXVI, IPS-CSIC, Santiago de Compostela, 1998, pp. 279-288.

${ }^{15}$ ARQUIVO HISTÓRICO UNIVERSITARIO. Op. cit.
} 
zaba (por segunda vez, como xa dixemos anteriormente) a construcción do edificio e a subasta das obras publicouse de novo no B.O.E. o 28 de agosto, agora baixo o presuposto de $1.237 .397,40$ pesetas. Foron concedidas a Juan Bouzón Figueroa e inauguráronse en marzo do ano seguinte, 1903, concedéndolle a honra da inauguración das mesmas ó seu promotor, Eugenio Montero Ríos.

\section{A CONSTRUCCIÓN DA ESCOLA}

A Inauguración foi finalmente fixada para o día 25 de marzo. A visita de Montero Ríos a Santiago con ocasión da inauguración das obras da Veterinaria, como se lle soía chamar, constitueu un auténtico acontecemento na historia da cidade. Viñeron Comisións representativas das catro provincias galegas para asistir ó acto e á chegada de Montero Ríos a Santiago o domingo 22 ás cinco do serán foi recibido na estación de Cornes por tódolos Concelleiros e Alcalde de Santiago e polas Comisiós e Xuntas Directivas de tódolos Centros e Sociedades da cidade. O pobo tamén foi a recibilo unha vez máis artellándose nunha grande manifestación popular e toda esta Comitiva cívica seguiu a Montero, acompañado polos seus xenros Manuel García Prieto e Eduardo Vincenti e polos seus fillos Avelino e Eugenio Montero Villegas, dende a estación de tren ata a casa do Deán e Cabildo da Catedral, Nicolás Rodríguez, íntimo de Montero Ríos, onde se hospedou nesta casión.

Ó día seguinte, o luns 23, ás doce da mañá desenvolveuse un Banquete popular na Bibilioteca da Universidade ${ }^{16}$ que foi artellado por unha Comisión organizadora ${ }^{17} \mathrm{e}$ para o que se abrira unha suscripción popular baixo $o$ prezo de 20 pesetas por persoa. No salón, que conta con 61 metros de lonxitude, instalouse unha mesa con forma de $\mathbf{E}$, inicial do nome do anfitrión, á que se sentaron 325 comensais (La Voz de Santiago, 28.03.1903) e o

${ }^{16}$ Hoxe, Biblioteca das Facultades de Xeografía e Historia da Universidade de Santiago de Compostela.

${ }^{17}$ Esta Comisión organizadora estaba composta polos Señores Ramón García Suárez, Miguel Amor, Arturo Somoza, José Parga Casal, Pedro Cayón, Leopoldo Sánchez Salgués, Vicente Fráiz Andón, Álvaro Caula e Jesús Landeira. En La Voz de Santiago, 28.03.1903. Biblioteca Penzol. Vigo.

«CUADERNOS DE ESTUDIOS GALLEGOS», Tomo XLIX, Fạscículo 115, Santiago 2002. 
servicio do banquete estivo a cargo do Hotel Suizo ${ }^{18}$ (Gaceta de Galicia, 27.03.1903). No intre dos brindis pronuniáronse pequenos discursos e verbas de homenaxe e agradecemento a Montero que tamén rematou por facer emprego da verba para dicir:

(...) Yo no he hecho en la vida más que cumplir con mi deber, aparte de que en varias ocasiones, como todo hijo de Adán haya faltado a él. Aqui he nacido, aqui adquirí mis primeras lecciones, (...) aqui he aprendido lo que sé, con lo cual he procurado contribuir a la prosperidad y al bienestar de mi Patria; y con esto no he hecho más que cumplir con el deber más elemental que tenemos todos los ciudadanos (...). (Gaceta de Galicia, 25.03.1903). (...) Laboremos todos para conseguir que donde vaya un gallego vaya un hombre ilustrado (...). (La Voz de Galicia, 27.03.1903).

Pola noite, os comerciantes e industriais de Compostela agasallaron cunha serenata ó Presidente honorario da Cámara oficial de Comercio, Industria e Navegación, e ó día seguinte, martes 24, tivo lugar un Mítin político no Teatro de Santiago onde Montero falou por primeira vez e despois de case cinco anos do Tratado de París ${ }^{19}$, facendo ademáis importantes declaracións sobre a sua figura como político:

\footnotetext{
${ }^{18} \mathrm{O}$ Hotel Suizo foi fundado por un suizo chamado Antonio Mengotti na Conga pero dende finais do século XIX o hotel foi trasladado polo fillo do fundador, Alfredo Mengotti, e a súa dona María Osende á rúa do Cardenal Payá, número 18, e mantívose aberto ata o ano 1936. O Suizo, como se lle chamaba en Santiago, tiña unha sona moi recoñecida, cun total de 36 habitacións distribuidas nos tres andares que se prolongaban na casa contigua da rúa dos Gramáticos e cunha cociña dotada de forno e de bos cociñeiros que con frecuencia preparaban os distintos menús e banquetes de sociedade que se celebraban na cidade. Ver PINTOS BARREIRO, M. G., A lume lento. Cen anos de hostelería en Compostela, Consorcio de Santiago, 1999. Pp. 49-51.

${ }^{19}$ E. Montero Ríos fora o presidente da Comisión española que viaxara a París para asinar o fin da loita con EEUU a propósito da independencia de Cuba e Filipinas. Este episodio trouxéralle unha inxusta impopularidade que el levara en silencio durante un tempo. Ver BARRAL MARTÍNEZ, M. e GARCÍA LÓPEZ, E., Discursos parlamentarios de Montero Ríos na Restauración borbónica (1874-1923), EGAP-Xunta de Galicia, Santiago de Compostela, 1999. Pp 241-251.
}

«CUADERNOS DE ESTUDIOS GALLEGOS», Tomo XLIX, Fascículo 115, Santiago 2002. 
Soy demócrata y soy liberal amosando tamén que as únicas ideas que profesa son las del partido liberal en que milito (...). Ese programa, que supongo todos conocéis, no es patrimonio mío, es del Partido Liberal. El Partido Liberal no aspira a entrar en la esfera religiosa, esa corresponde a la Iglesia exclusivamente (...). En cuanto a las aspiraciones respecto al orden social (...) todo lo que sea compatible con el respeto que se debe al derecho sagrado de los demócratas, entiende el Partido Liberal que debe hacer el Estado en pro de las clases desheredadas. Debemos, pues, consagrarnos a su educación, a su instrucción, a elevar su nivel intelectual y a mejorar su situación económica, reconociendo bien las necesidades de la nueva vida (...). Franquear los caminos a todos para que puedan llegar a ser propietarios, contribuir también por los medios lícitos a que su trabajo sea dignamente recompensado, y esto sin emplear violencia que a nada ventajoso pueda conducir, es otra de las aspiraciones del Partido Liberal (...). El sufragio universal se impone en la vida moderna, no hay más remedio que admitirlo, que ejercitarlo, que amoldar a él todas las instituciones de la vida social y política (...). Ahora queremos gobernarnos a nosotros mismos, tenemos perfecto derecho para ello (...). El cuartel es una gran escuela de disciplina y de obediencia, y el Partido Liberal aspira al servicio y a la instrucción militar obligatorios. (Gaceta de Galicia, 25.03.1903). (...) Hagamos votos, sí, para que la flamigera espada que hay que empuñar, sea igual a la que Santiago llevaba en Clavijo cuando huian las huestes sarracenas, pues si aquellos cristianos peleaban por la reconquista de su pueblo, nosotros luchamos ahora con otras turbas más terribles que son las del caciquismo, que guerreando en semicírculo como los hijos del Koran, quiera hacernos tributarios de sus ambiciones (Gaceta de Galicia, 27.03.1903).

(...) de lo que me enorgullezco y entiendo que ha de ser un titulo legítimo para que mis hijos se enorgullezcan también, es de haber ido a París a representar a mi querida Patria, que se halla sumida en la amargura, a hacer mios sus dolores y a salvar de aquel naufragio los restos que me fuera posible con mi entusiasmo, con mi voluntad y con mi decisión. Yo no había sido partidario de la guerra, (...) yo había sido partidario de la autonomía (que non independencia) de nuestras colonias(...) (La Voz de Santiago, 28.03.1903).

«CUADERNOS DE ESTUDIOS GALLEGOS», Tomo XLIX, Fascículo 115, Santiago 2002. 
A inauguración das obras propiamente ditas desenvolveuse o día 25 e ainda que nun principio se tiña proxectado que fose ás 10 da mañá, a forte choiva que caeu en Santiago ese día fixo que o acto de inauguración se aprazara para as tres da tarde; celebrouse antes o Banquete de rigor, no Pazo de Raxoi nesta ocasión, onde tamén se deron pequenos discursos e verbas de agradecemento ó prócer galego, sobre todo por parte do Alcalde, Marqués de Casa Pardiñas, e do Rector da Universidade, Francisco Romero Blanco. Montero tamén pronunciou unhas verbas nas que deixou constancia da sua condición de católico e progresista:

(...) La religión guió los primeros pasos de mi infancia, que a ella debo los sentimientos que he tenido siempre y a la moral cristiana a la cual habré faltado como todos los hijos de Adán, pero que siempre ha sido la Estrella polar de mi conducta, después me entregaron a la Universidad y entonces conocí cuales son las dos grandes verdades, de las que una está más allá del sepulcro: la fe y la ciencia. Y no concibo que pueda haber antagonismo entre ellas (...). Soy profundamente católico pero como hombre soy progresivo (...). Nosotros, los que vivimos en estos tiempos, los que nos inspiramos en la verdad eterna, creemos que nuestra insignia está escrita hace 1903 años, en aquellas santas palabras: discite á me finit nulis sum et humilis corde, palabras de amor a nuestros semejantes; palabras de amor al desgraciado y al humilde (...). Concluyo rogando a todos ustedes que me consideren como el más humilde pero el más entusiasta español, gallego y santiagués ${ }^{20}$.

Ó remate do Banquete os convidados concurriron en automóbil á rúa do Hórreo ${ }^{21}$, onde se atopaba o solar do edificio, e o acto da inauguración propiamente dito, aínda que estivo cheo de solemnidade, desensenvolveuse de xeito lixeiro e mesmo precipitado por temor a que comezase a chover

${ }^{20}$ ARQUIVO HISTÓRICO UNIVERSITARIO. Op. cit.

${ }^{21}$ A Comitiva cívica tiña proxectado facer o percorrido a pé, dende o Pazo de Raxoi, pasando pola Praza do Hospital (Praza do Obradoiro actual), Praterías, Rúa do Vilar, Praza do Toural e Rúa do Hórreo, onde se atopaba o solar do novo edificio que se ía a construir, pero o mal tempo fixo que se mudasen estes preparativos e se fixese o itinerario en coche.

«CUADERNOS DE ESTUDIOS GALLEGOS», Tomo XLIX, Fascículo 115, Santiago 2002. 
dun intre a outro. Montero colocou un anaco de granito labrado ${ }^{22} \mathrm{e}$ no intre no que o contratista da obra Juan Bouzón Figueroa lle ía entregar unha paleta de prata nunha bandexa con argamasa de cal, o anfitrión empregou a súa man dereita para extender o xeso, ó tempo que dicía así es como se honra el oficio de cantero. (Gaceta de Galicia, 28.03.1903).

Ás seis do serán Montero volveu á granxa de Lourizán dende a estación de Cornes e baixos os acordes da Marcha Real, igual que cando foi recibido o día 22, pero neste intre a choiva tamén fixo que o momento da despedida non fora lucido e solemne coma se agardaba. Según amosa a prensa local, a impresión que Montero levaba dos acontecementos desenvolvidos en Santiago entre o día 22 e o 25 de marzo reflectiuno o prócer nunha soa verba: Archicontento, dixo, de mis paisanos y de mi inolvidable pueblo, y si encuentra usted otra palabra más expresiva, esa es la que quise emplear. (La Voz de Santiago, 28.03.1903).

As situacións polas que tivo que pasar a construcción da Escola de Veterinaria antes da súa posta en funcionamento foron longas e complexas; a inauguración da Escola propiamente dita, o 2 de outubro de 1915 e cando xa facelecera Montero ${ }^{23}$, foi un acto que xa non revisteu a grande solemnidade que caracterizara a inauguración das obras. Os tempos comezaran a mudar e ainda que se congregaron representacións da Veterinaria española e o pobo de Santiago acudeu en masa á apertura do primeiro curso (1915-1916) deste novo Centro docente ${ }^{24}$, temos a sensación de que o que interesaba agora era sobre todo o senso do edificio en sí, é dicir, o importante que era para a rexión galega o poder contar cunha

\footnotetext{
${ }^{22}$ As medidas do bloque eran de 40 por 50 centímetros.

${ }^{23}$ E. Montero Ríos morreu en Madrid o 12 de maio de 1914, ós 82 anos de idade e detentando os cargos de Senador vitalicio e Presidente da Sección do civil da Comisión xeral de Codificación; o seu cadaleito chegou en tren a Pontevedra e de alí foi ó seu Pazo de Lourizán para ser soterrado nun foxo que el mesmo mandara construir no panteón familiar.

${ }^{24}$ Algúns dos personaxes máis ou menos significativos que estiveron presentes neste acto de Inauguración da Escola foron por exemplo o Rector, Cleto Troncoso, ademáis de todo o Claustro universitario e Directores dos demáis Centros docentes de Santiago, o concelleiro e xornalista Antonio Fernández Tafall, que levaba o pendón da cidade, o Alcalde accidental A. Novo Campelo, o catedrático de Dereito Vicente López Mosquera, que tamén pronuinciou un discurso agredecendo a presencia de tódolos asistentes e ós Centros que alí se representaban, e o Comisario Rexio, en representación do Ministro de Instrucción.
}

«CUADERNOS DE ESTUDIOS GALLEGOS», Tomo XLIX, Fascículo 115, Santiago 2002. 
Escola de Veterinaria máis que o promotor da mesma obra, que comezaba agora a simbolizar o caciquismo e a corrupción política da Restauración. Neste acto tamén se descubriu unha lápida adicada a Montero e o seu fillo Avelino, Deputado por Mondoñedo e Lugo, pronunciou un discurso en memoria do seu pai ó tempo que amosou o importante papel que tiña o coñecemento e estudio da Veterinaria no desenvolvemento do país en xeral e de Galicia en particular.

Según M. Rodríguez García, nunha extensión total de 65.544 metros cadrados, o edificio ten 116 metros cadrados de fachada, 64 de fondo e 7.424 de extensión superficial. Consta de dous pisos. No piso baixo ten dez cortes, con sitio para 44 cabezas; seis cuartos destiñados a anfiteatro anatómico, consulta clínica, sala de operacions, botiquin, departamento de hidroterapia, leitería e preparación de alimentos; e cuartos para o conserxe, para o porteiro e para os alumnos internos. No piso principal hai trinta e seis locais destiñados a cátedras, bibliotecas, laboratorios, museos, oficina, arquivo, secretaría, dirección, sala de profesores e de actos, etc. Os edificios secundarios son: dous pavillóns de 128 metros cuadrados cada un, destiñados a clínica de enfermidades contaxiosas; outro, de 374 metros, construido para taller de ferrar e fragua, con dous depósitos de auga, baño para animais, etc. A horta ten unha extensión de máis de catro hectáreas, sen contar o espacio destiñado a xardín. Hai ademáis seis currais que miden en conxunto 5.160 metros cadrados. As obras custaron 1.600.000 pesetas (Rodríguez García, M, 1994. P. 34).

Dende o punto de vista externo, xa dixemos que o primeiro proxecto elaborado polo arquitecto Antonio Bermejo Arteaga en 1894 estaba inspirado na Escola francesa de Alfort; un complexo dun edificio principal, a Escola propiamente dita, de planta rectangular, dous pisos de altura e patio interior, onde sobresaen cara fora os corpos dos extremos e os centrais. Pero esta primeira idea sofreu unha pequena modificación no seu corpo central cando Arturo Calvo pasou a ser o encargado, implantando as catro pilastras que recorren toda a súa altura e un ático que albergaba un escudo con figuras de Rafael de la Torre Mirón e que foron eliminadas trala conversión do edificio na Sede do Parlamento de Galicia.

Os grandes eloxios e loubanzas cas que a prensa rexional e a opinión pública en xeral acolleu a construcción e desenvolvemento da Escola non se corresponderon sen embargo ca pouca vida que o centro tivo como

«CUADERNOS DE ESTUDIOS GALLEGOS», Tomo XLIX, Fascículo 115, Santiago 2002. 
Escola de Veterinaria. Dende a inauguración do curso en 1915 e ata o ano 1924 funcionou coma tal, pero neste derradeiro ano o Directorio Militar presidido polo Xeneral Primo de Rivera, co pretexto do reducido número de alumnos matriculados nos cursos que se sucederan dende a súa inauguración, fixo desaparecer dos presupostos para 1924-1925 a partida destiñada a esta Escola, quedando suprimada e sendo trasladado todo o seu material científico e bibliográfico ás outras catro escolas de veterinaria existentes no Estado ${ }^{25}$, as de Madrid, Zaragoza, Córdoba e León.

O Concello rematou por solicitar un novo destiño para o edificio e compensar quizais a doación dos terreos que fixera e como por aquel entón se estaban a crear novos Corpos de Artillería solicitouse un para Santiago. Este foi concedido de seguido, aloxándose na antiga Escola de Veterinaria e no mesmo ano 1924 o Reximento de Artillería da Campañía $\mathrm{n}^{\circ} 28$ e o Edificio pasou así a pertencer ó Estado e funcionou como Cuartel militar ata 1988, ano no que pasou a ser a Sede do Parlamento de Galicia $^{26}$, chegando ata hoxe.

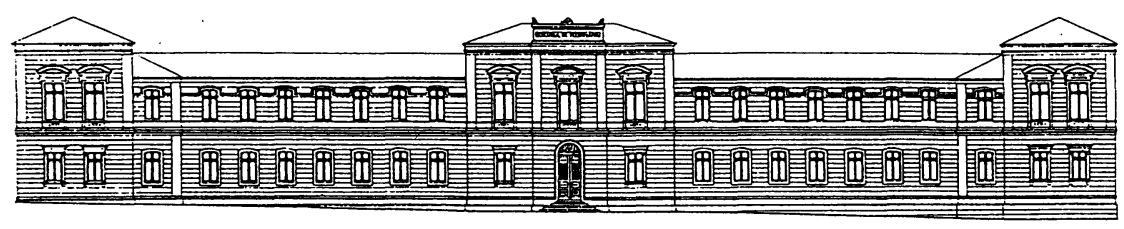

Fig. 1: Alzado do edificio para Escola de Veterinaria. Fonte: Gaceta de Galicia, 25.03.1903.

\footnotetext{
${ }^{25}$ R.O. do 22 de xullo de 1924.

${ }^{26}$ Anteriormente atopábase no Pazo de Xelmírez, a súa primeira sede tralo seu nacemento en 1881, logo despois no Colexio de Fonseca e a derradeira sede que chega ata hoxe é a do antigo edificio da Escola de Veterinaria.
}

«CUADERNOS DE ESTUDIOS GALLEGOS», Tomo XLIX, Fascículo 115, Santiago 2002. 


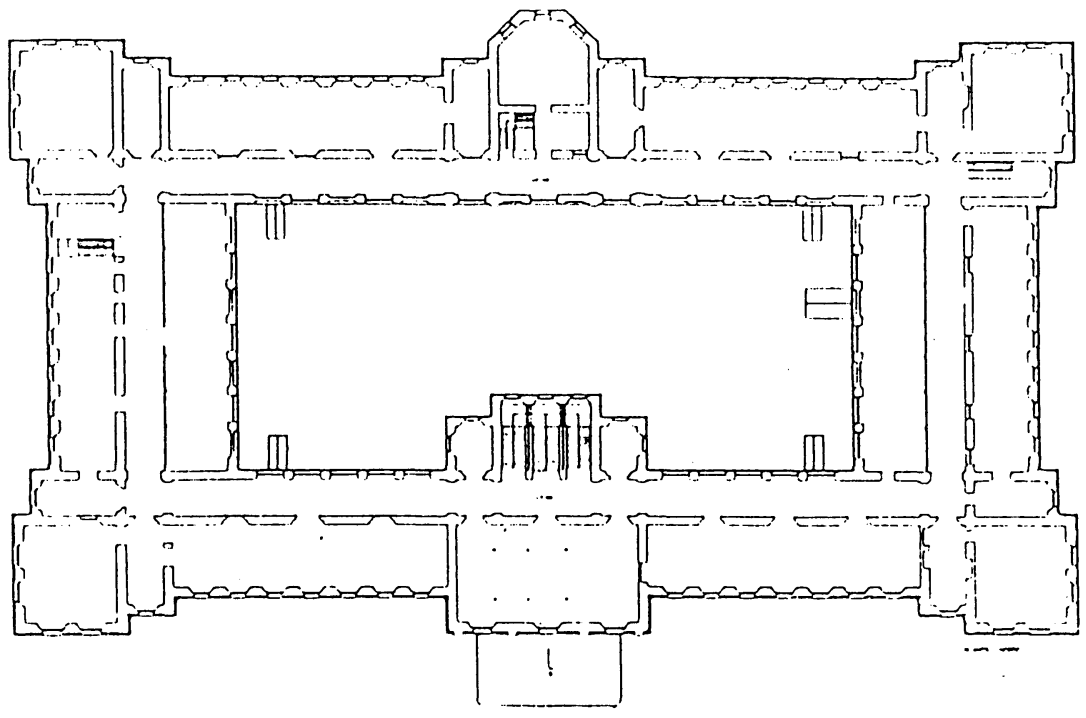

Fig. 2: Planta orixinal do edificio da Escola de Veterinaria.

Fonte: Costa Buján, P, Santiago de Compostela, 1850-1950.

Desenvolvemento urbano. Outra arquitectura, Santiago, 1989. P. 149.

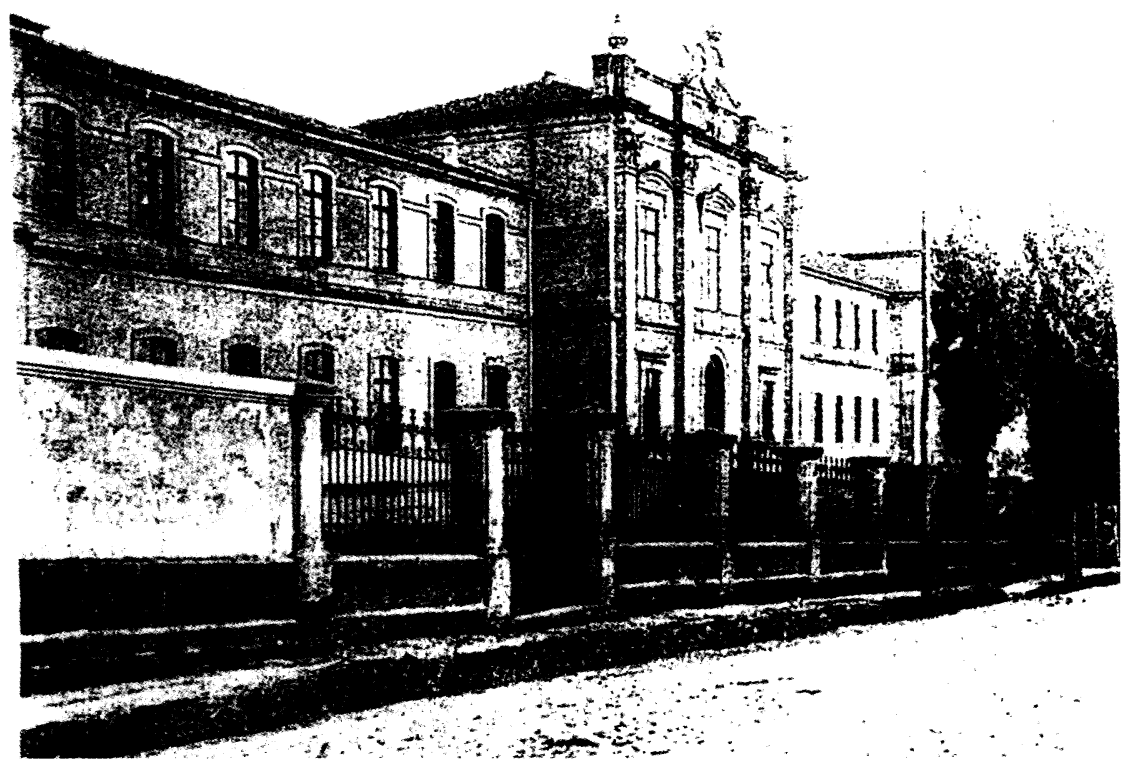

Fig. 3: A Escola de Veterinaria. 1903 Ca. Fonte: Costa Buján, P., op. cit. P. 146.

«CUADERNOS DE ESTUDIOS GALLEGOS», Tomo XLIX, Fascículo 115, Santiago 2002. 


\section{BIBLIOGRAFÍA}

ARCO, J. (1947), Montero Ríos, Col. Medio Siglo de Historia, Ed. Purcalla, Madrid.

BARRAL MARÍNEZ, M. (1998), «O Mecenado de montero Ríos na Universidade de Santiago», en Revista Semata, ${ }^{\circ} 10$, Cultura , poder y mecenazgo, Universidade de Santiago.

BARRAL MARTÍNEZ, M, e GARCÍA LÓPEZ, E. (1999), Discursos parlamentarios de Montero Ríos na Restauración borbónica, (1874-1923). Ed. EGAP-Xunta de Galicia, Santiago.

BARREIRO FERNÁNDEZ, X. R. (1983), Historia Contemporánea de Galicia. Vol. III e IV, Ed. Gamma, A Coruña.

- Idem (1991), Historia Contemporánea. Enseñanza y Cultura, en Galicia. Historia, Vol. VII, Ed. Hércules, A Coruña.

- Idem, (Dir.), (1997), «Caciquismo e funcionariado en Galicia no século XIX», en III Simposio de Historia da Administración Pública. Col. Xornadas e Seminarios, Ed. EGAP-Xunta de Galicia, Santiago.

CABEZA DE LEÓN, S. (1947), Historia de la Universidad de Santiago. 3 Vol. Santiago.

CARASA SOTO, P. (Edit), (1994), Élites. Prosopografía contemporánea. Serie: Historia y Sociedad, Universidad de Valladolid.

CORES TRASMONTE, B. (1998), Os Senadores da Universidade de Santiago, Cuadernos de Estudios Gallegos. Anexo XXVI. IPS-CSIC, Santiago.

CARNERO, T. (1998), «El reinado de Alfonso XIII», Revista Ayer, $\mathrm{n}^{\circ} 28$, Madrid.

COSTA BUJÁN, P. (1989), Santiago de Compostela 1850-1950. Desenvolvemento urbano. Outra Arquitectura, Colexio Oficial de Arquitectos de Galicia, Santiago.

«CUADERNOS DE ESTUDIOS GALLEGOS», Tomo XLIX, Fascículo 115, Santiago 2002. 
DÍAZ Y DÍAZ, M.C. (Coord), (1980), La Universidad de Santiago. Ed. Universidad de Santiago.

DURÁN, J. A. (1986), Crómicas IV. Conflicto de hoy, historias románticas y diarios modernos, Ed Akal, Madrid.

FERNÁNDEZ FERNÁNDEZ, X. (1996), Arquitectura del Eclecticismo en Galicia (1875-1914). 2 vol. Ed. Universidade da Coruña, A Coruña.

LÓPEZ CORDÓN, Mª V. (1976), La Revolución de 1868 y la I Repúbli$c a$, Ed. Siglo XXI, Madrid.

MARTÍNEZ VAL, J. Mª (1980), Montero Ríos y su tiempo. Madrid.

PÉREZ BUSTAMANTE, C. e GONZÁLEZ GARCÍA-PAZ, S. (1934), La Universidad de Santiago de Compostela. (El pasado y el presente). Universidad de Santiago.

PINTOS BARREIRO, M. G. (1999), A lume lento. Cen anos de hostelería en Compostela, Consorcio de Santiago.

ROBLES EGEA, A. (Comp.), (1996), Politica en Penumbra. Patronazgo y clientelismo político en la España Contemporánea. Ed. Siglo XXI, Madrid.

RODRÍGUEZ GARCÍA, M. (1994), Historia da Escola de Veterinaria de Santiago (1882-1924). Ed. Universidade de Santiago, Santiago de Compostela.

VARELA ORTEGA, J. (1977), Los amigos políticos: Partidos, elecciones y caciquismo en la Restauración (1875-1900). Ed. Alianza, Madrid.

VARELA ORTEGA, J, DARDÉ, C, e CARNERO, T. (1997), Política en la Restauración (1875-1923). Sistema politico y elecciones. Documentos de Trabajo, vol. 1. Instituto Universitario Ortega y Gasset, Madrid. 
VARELA GONZÁLEZ, I. (1989), La Universidad de Santiago. 19001936. Reforma universitaria y conflicto estudiantil. Ed. do Castro, A Coruña.

VILA JATO, Ma . D. (Coord.), (1996), O Patrimonio histórico da Universidade de Santiago de Compostela. 2.vol. Ed. Parlamento de Galicia, Santiago de Compostela.

VILLARES PAZ, R. (1998), «Política y Mundo rural en la España contemporánea. Algunas consideraciones historiográficas», Ecole Française de Roma.

VV AA. (1997), Poder local, élites e cambio social na Galicia non urbana (1874-1936), Parlamento de Galicia-Universidade de Santiago.

YANINI, A. (1984), El Caciquisme, Valencia.

\section{FONTES}

ARQUIVO HISTORICO UNIVERSITARIO. Santiago de Compostela.

- SERIE UNIVERSIDAD.

- FONDO MUNICIPAL.

a. Consistorios.

b. Edificios.

XORNAIS E REVISTAS

a. HEMEROTECA UNIVERSITARIA. Santiago de Compostela.

- El Eco de Santiago.

- Gaceta de Galicia.

- La Voz de Galicia.

b. MUSEO PROVINCIAL DE PONTEVEDRA. Pontevedra.

- Diario de Pontevedra.

c. BIBLIOTECA PENZOL. Vigo.

- La Voz de Santiago.

«CUADERNOS DE ESTUDIOS GALLEGOS», Tomo XLIX, Fascículo 115, Santiago 2002. 